\title{
The effect of test conditions on failure parameters during uniaxial compression of potato tissue
}

\author{
Wenceslao Canet, ${ }^{1}$ M. Dolores Alvarez ${ }^{1} *$ \& Manuel Juan Gil $^{2}$ \\ 1 Department of Plant Foods Science and Technology, Instituto del Frío-CSIC, José de Novaís no 10, E-28040 Madrid, Spain 2 Deceased (2004)
}

(Received 15 March 2006; Accepted in revised form 18 December 2006)

Summary Uniaxial compression tests were performed on potato flesh. Cylindrical samples of diameters (19.05 and $25.4 \mathrm{~mm})$ and heights $(5,10,15$ and $20 \mathrm{~mm})$ were tested under non-lubricated, lubricated and increased friction conditions. The deformation rate effect was also examined by performing compression tests at 50 , 100, 200 and $400 \mathrm{~mm} \mathrm{~min}^{-1}$. In the present study, parameters derived from compression to failure were failure strain $(\varepsilon)$, engineering stress $\left(F / A_{0}\right)$, true stress $\left(F / A_{\mathrm{f}}\right)$, apparent elastic modulus $(E)$ and energy at failure $\left(U_{\mathrm{v}}\right)$. As compared with non-lubricated friction condition, lubrication increased significantly the average $\varepsilon$ value and decreased significantly the average $F / A_{\mathrm{f}}$ value, but appears to have lower significant effect on the average $F / A_{0}, E$ and $U_{\mathrm{v}}$ values. Failure strain, engineering stress and energy at failure increased with deformation rate, whereas true stress and apparent elastic modulus decreased. Failure strain increased with sample diameter and decreased significantly with sample height, whereas the rest of the failure parameters decreased when both sample dimensions increased. As compared with non-lubricated friction condition, lubrication results in a higher influence of deformation rate on the average $\varepsilon, F / A_{0}$ and $U_{\mathrm{v}}$ values, a similar influence of sample diameter on the average $F / A_{\mathrm{f}}$ and $E$ values, but a lower influence of sample height on all the failure parameters. In turn, increased friction results in a higher influence of deformation rate and mainly the sample height on the average $\varepsilon, F / A_{0}$ and $U_{\mathrm{v}}$ values, but a lower influence of sample diameter on all the failure parameters. Principal components analyses showed that principal component 1 is determined by $\varepsilon, F / A_{0}$ and $U_{\mathrm{v}}$, and is strongly influenced by sample height, whereas component 2 is dominated by $E$, and is mainly influenced by sample diameter.

Keywords Deformation rate, friction, lubrication, potato tissue, principal components analysis, sample dimensions, uniaxial compression.

\section{Introduction}

The uniaxial compression test is the most popular means of deriving the stress-strain properties of soft foods and of biological materials in general; other methods like texture profile analysis (TPA) and stress relaxation are based on the compression test (Alvarez \& Canet, 1998; Canet et al., 2005). The drawback of the compression test however is that the friction between the sample and the loading plates leads to an inhomogeneous stressstrain state in the sample (Charalambides et al., 2001). Thus, the force registered during the uniaxial compression test is attributed to the sum of the force actually involved in compressing the food plus the force required to overcome the surface friction as the sample expands between the plates (Canet \& Sherman, 1988, 1990; Wagoner \& Chenot, 2005). The consequence of this

*Correspondent: Fax: +3491 5493627;

e-mail: ifrat44@if.csic.es effect is the 'barrel shape' of a compression-loaded cylindrical specimen observed during tests. If compression is performed under conditions where there is no friction, the deformation is homogeneous and the sample retains its cylindrical shape (Charalambides et al., 2001). The frictional effects between the plates and the sample have been well documented in the literature (Johnson \& Mellor, 1973; Dieter, 1986; Smith \& Kobayashi, 1993). Specifically, the material next to the plates is restrained from radial movement, and the material appears to be stiffer than it truly is. This leads to 'apparent' as opposed to 'true' stress-strain calculations, when the usual expressions for stress and strain and the experimental force-deformation data are used (Canet et al., 2001; Charalambides et al., 2005).

The apparent stress-strain behaviour will also depend on the geometry, such behaviour being an indication of inhomogeneous deformation (which in compression can be the result of friction at the interface). It has been shown that sample dimensions influence the force- 
deformation data obtained when large forces are applied (Culioli \& Sherman, 1976; Olkku \& Sherman, 1979; Chu \& Peleg, 1985; Canet \& Sherman, 1988, 1990; Gil, 1991; Charalambides et al., 2001, 2005). Also, previous works have shown that the rate of deformation can affect the measured rheological properties from compression tests (Goh \& Sherman, 1987; Luyten et al., 1992; Scanlon \& Long, 1995; Alvarez et al., 2002).

The influence of surface friction and lubrication on the compression behaviour at compression rates of 5-100 $\mathrm{mm} \mathrm{min}^{-1}$, of cylindrical samples of potato flesh (cv. King Edward) was previously examined for samples having length/diameter ratios of $0.2-0.8$ (Canet \& Sherman, 1988). In this study, the experiments of compression tests with potatoes (cv. Desiree) were performed with larger ranges, either of compression rate or of sample dimensions. Besides, in a previous work, a method was established for determining dimensionless area expansion ratio at failure, $A_{\mathrm{f}} / A_{0}$ (actual maximum area of the deformed sample in contact with the loading platens/original area of the non-deformed sample) (Canet et al., 2006). The determination of area expansion ratio at failure allows a direct determination of true stress $\left(F / A_{\mathrm{f}}\right)$ from engineering stress $\left(F / A_{0}\right)$, justifying the use of this additional parameter in relation to failure under compression tests. A recent International Technical Specification describes a method for the determination of rheological properties by uniaxial compression tests at constant displacement rate of hard and semi-hard cheeses [ISO/TS 17996/IDF/RM 205:2006(E)]. However, such standardised testing protocol for potatoes does not exist and needs to be established.

Principal components analysis (PCA) is used to study the interdependencies and underlying relationships between variables (Piggot \& Sharman, 1986), being widely applied in studies on semisolids or liquid products, such as wine and apple juices (Silva \& Macalta, 1999; Varela et al., 1999). PCA is also used to analyse the sensory properties of fruits and vegetables to investigate the relationship with instrumental measurements (Barreiro et al., 1998).

The purpose of the present study was: (1) to establish how key failure parameters derived from compression tests on potatoes are influenced by the surface friction conditions, rate of deformation and sample diameter and height; and (2) to use PCA to reduce the number of failure parameters by means of linear combinations of the same.

\section{Materials and methods}

\section{Test material}

Data were obtained using Spanish potato tubers (Solanum tuberosum, L., cv. Desiree), having weights (g) within the confidence interval $(255.69 \leq \mu \leq 311.81)$ and specific weights $\left(\mathrm{g} \mathrm{cm}^{-3}\right)$ within the interval $(1.0681 \leq \mu \leq 1.0737) ; \quad P \leq 0.01$. The material was stored for 2 months at about $5{ }^{\circ} \mathrm{C}$ and $85 \%$ relative humidity to avoid sprouting and accumulations of sugars before the experiment (Smith, 1987). Each day prior to testing, potatoes were reconditioned at room temperature for about overnight. Then, cylinder-shaped samples, having diameters, $\emptyset 19.05$ and $25.4 \mathrm{~mm}$ were cut from the central region of potatoes by cork borers and then trimmed to heights, $h$ of $5,10,15$ and $20 \mathrm{~mm}$ (Gil, 1991). The exact height of each sample was recorded to within $\pm 0.1 \mathrm{~mm}$. In order to avoid drying, the samples were kept between wet sponges for less than $20 \mathrm{~min}$ prior to testing.

\section{Uniaxial compression test}

A minimum of ten samples of each geometry $(n=10)$ were compressed at room temperature $\left(20-21^{\circ} \mathrm{C}\right)$ between the metal platens of a model 1140 Instron Universal Testing Machine (Instron, Canton, Mass., USA) using a 5-kN load cell and a $57-\mathrm{mm}$ diameter flat compression plunger (Canet et al., 2006). Experiments were carried out at constant deformation rates, $R_{\mathrm{d}}$ of 50 , 100, 200 and $400 \mathrm{~mm} \mathrm{~min}^{-1}$. The force-deformation behaviour was recorded with a standard Instron recorder at a speed of 1:10 with respect to the deformation rate. Compression tests were carried out using three frictional conditions. Firstly, 32 tests (four deformation rates $\times$ two diameters $\times$ four heights) were performed where no lubricant was applied to the loading platensample interface before testing (non-lubricated friction condition). Additional 32 tests were carried out with each sample's upper and lower surfaces lubricated with mineral oil, having a viscosity of $30 \mathrm{~mm}^{2} \mathrm{~s}^{-1}$ (lubricated friction condition). Finally, 32 tests were carried out with increased friction by inserting two sheets of emery paper (grit size 150) between the loading platens and upper and lower surfaces of each sample (increased friction condition). Therefore, a total of 960 cylindrical specimens were tested.

The force-deformation data were converted into compressive stress and Cauchy strain. Five parameters were identified to characterise the compression stressstrain curves (Smith \& Kobayashi, 1993; Luginbühl, 1996; Canet et al., 2001, 2005):

1. The Cauchy strain at failure (failure strain) is defined as $\varepsilon=($ final height - initial height)/(initial height).

2. The apparent failure stress, defined as engineering stress $\sigma=F / A_{0}$ (force at failure divided by the original cross section expressed in $\mathrm{kPa}$ ).

3. The true failure stress defined as true stress, $\sigma_{t}=F / A_{\mathrm{f}}$ (force at failure divided by the surface area at failure expressed in $\mathrm{kPa}$ ). This failure parameter was only 
determined under non-lubricated and lubricated friction conditions as published before (Canet et al., 2006).

4. The apparent elastic modulus $E$ was determined from the linear portion of the derived compressive stressstrain curve and is expressed in $\mathrm{kPa}$.

5. The apparent energy at failure $U_{\mathrm{v}}$, defined as the total work of deformation divided by the original sample volume and expressed in $\mathrm{kJ} \mathrm{m}^{-3}$.

\section{Statistical analysis}

Different statistical analyses for determining the variation of failure parameters with friction conditions, deformation rate and sample dimensions were carried out by using STATGRAPHICS (version 5.0, STSC Inc., Rockville, MD, USA). The failure parameters were subjected to the different multifactor analyses of variance (ANOVA) and PCA showed in the Table 1. In the multifactorial analyses, where significant differences were present, individual combinations were compared using Bonferroni multiple range tests (99\%). The factorial analyses were used to study the effect of test conditions on the failure parameters, whereas the PCA analyses were carried for investigating the interdependence of the same via identification of new, uncorrelated variables (Alvarez \& Canet, 2000).

\section{Results and discussion}

\section{Friction, deformation rate and sample dimension effects}

As shown in Table 2, for non-lubricated and increased friction conditions, there is a significant $(P \leq 0.01)$ effect of deformation rate, and sample diameter and height on

Table 1 Statistical analysis carried out in the study on the failure parameters

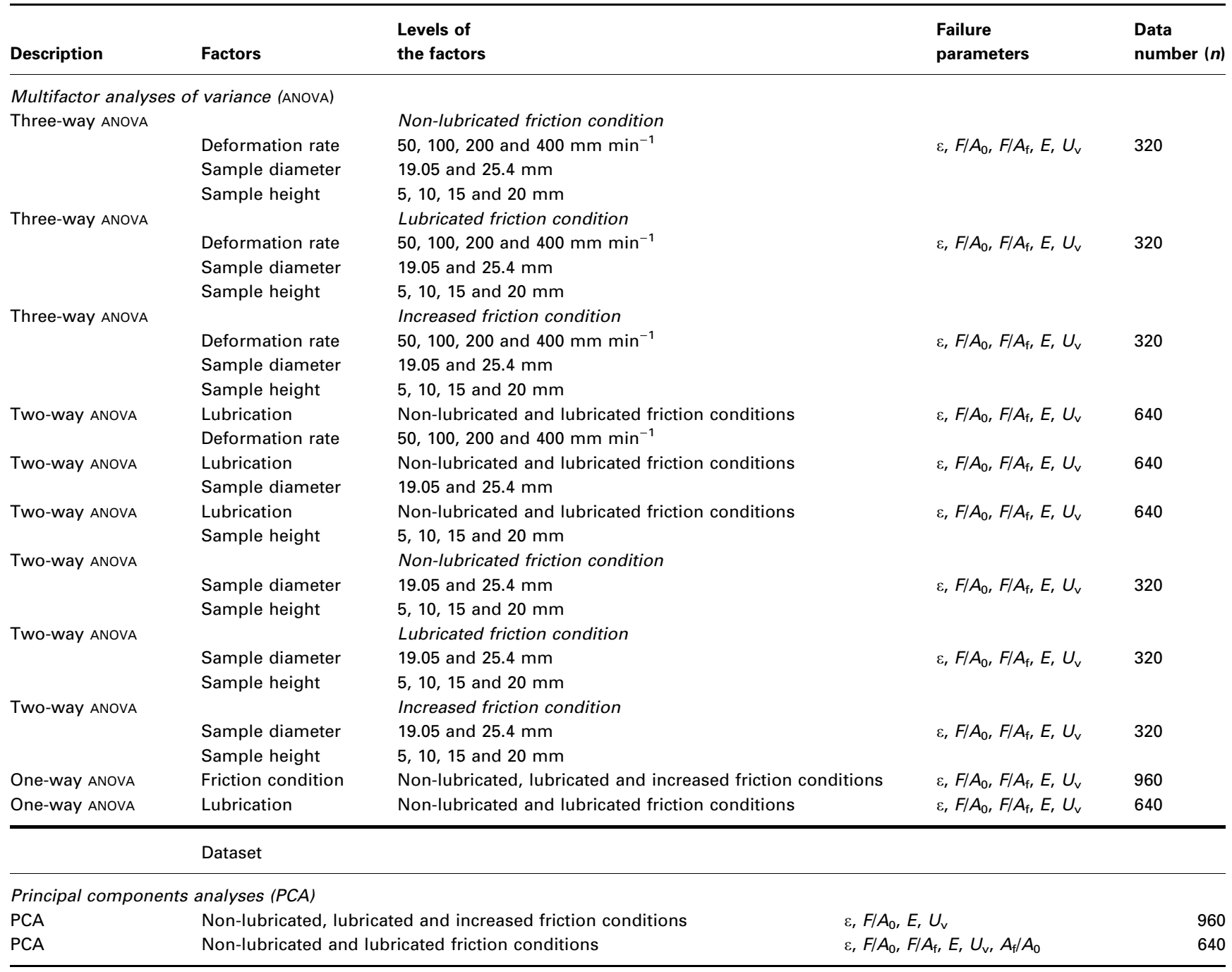


Table 2 Multifactor analyses of variance (three-way ANOvA) for the failure parameters $\left(\varepsilon, F / A_{0}, F / A_{\mathrm{f}}, E, U_{\mathrm{v}}\right)$ under non-lubricated, lubricated and increased friction conditions

\begin{tabular}{|c|c|c|c|c|c|c|c|}
\hline \multirow[b]{2}{*}{ Source of variation } & \multirow[b]{2}{*}{ Failure parameters } & \multicolumn{2}{|c|}{$\begin{array}{l}\text { Non-lubricated friction } \\
\text { condition }\end{array}$} & \multicolumn{2}{|c|}{$\begin{array}{l}\text { Lubricated friction } \\
\text { condition }\end{array}$} & \multicolumn{2}{|c|}{$\begin{array}{l}\text { Increased friction } \\
\text { condition }\end{array}$} \\
\hline & & F-ratio & Sig. level & F-ratio & Sig. level & F-ratio & Sig. level \\
\hline \multicolumn{8}{|l|}{ Main effects } \\
\hline \multirow[t]{5}{*}{ A: deformation rate } & $\varepsilon$ & 20.137 & 0.0000 & 44.479 & 0.0000 & 85.908 & 0.0000 \\
\hline & $F / A_{0}$ & 17.026 & 0.0000 & 48.901 & 0.0000 & 89.670 & 0.0000 \\
\hline & $F / A_{\mathrm{f}}$ & 59.913 & 0.0000 & 89.670 & 0.0000 & - & - \\
\hline & $E$ & 20.251 & 0.0000 & 21.932 & 0.0000 & 30.519 & 0.0000 \\
\hline & $U_{v}$ & 27.031 & 0.0000 & 53.531 & 0.0000 & 125.769 & 0.0000 \\
\hline \multirow[t]{5}{*}{ B: diameter } & $\varepsilon$ & 7.874 & 0.0054 & 5.607 & $0.0186^{*}$ & 60.848 & 0.0000 \\
\hline & $F / A_{0}$ & 212.591 & 0.0000 & 196.567 & 0.0000 & 195.008 & 0.0000 \\
\hline & $F / A_{\mathrm{f}}$ & 693.797 & 0.0000 & 744.981 & 0.0000 & - & - \\
\hline & $E$ & 44.200 & 0.0000 & 82.468 & 0.0000 & 39.307 & 0.0000 \\
\hline & $U_{v}$ & 37.438 & 0.0000 & 42.321 & 0.0000 & 16.018 & 0.0000 \\
\hline \multirow[t]{5}{*}{ C: height } & $\varepsilon$ & 467.853 & 0.0000 & 416.956 & 0.0000 & 1304.654 & 0.0000 \\
\hline & $F / A_{0}$ & 256.011 & 0.0000 & 92.676 & 0.0000 & 1782.949 & 0.0000 \\
\hline & $F / A_{\mathrm{f}}$ & 179.028 & 0.0000 & 58.483 & 0.0000 & - & - \\
\hline & $E$ & 20.254 & 0.0000 & 17.702 & 0.0000 & 17.132 & 0.0000 \\
\hline & $U_{v}$ & 575.233 & 0.0000 & 321.603 & 0.0000 & 2038.842 & 0.0000 \\
\hline
\end{tabular}

*Non-significant differences between means $(P \leq 0.01)$; factors and levels: deformation rate $\left(50,100,200\right.$ and $\left.400 \mathrm{~mm} \mathrm{~min}^{-1}\right)$; diameter $(19.05$ and $25.4 \mathrm{~mm})$; height $(5,10,15$ and $20 \mathrm{~mm}) ;(n=320)$.

all the failure parameters $\left(\varepsilon, F / A_{0}, F / A_{\mathrm{f}}, E\right.$, and $U_{\mathrm{v}}$, and $\varepsilon, F / A_{0}, E$, and $U_{\mathrm{v}}$, respectively). For lubricated friction condition, there is additionally a significant $(P \leq 0.01)$ effect of deformation rate and sample diameter and height on the average $F / A_{0}, F / A_{\mathrm{f}}, E$, and $U_{\mathrm{v}}$ values; sample diameter did not have significant effect on the average $\varepsilon$ value. As compared with samples compressed without lubricant, lubrication results in a higher significant influence of deformation rate, a non-significant influence of sample diameter and a lower significant influence of sample height on the failure strain. Increased friction results in a very much higher significant influence of the three factors on the average $\varepsilon$ value (Table 2). In turn, as compared with non-lubricated friction condition, lubrication results in a higher significant influence of deformation rate and a lower significant influence of sample diameter and height on the engineering stress (Table 2), whereas increased friction results in a very much higher significant influence of deformation rate and sample height and a lower significant influence of sample diameter on the average $F / A_{0}$ value. Also lubrication results in a higher significant influence of deformation rate and sample diameter, but a lower influence of sample height on the true stress $\left(F / A_{\mathrm{f}}\right)$. Likewise, as compared with samples compressed without lubricant, lubrication results in a similar influence of deformation rate and sample height and a higher significant influence of sample diameter on the average $E$ value. Increased friction results in a similar significant influence of the three factors studied on the apparent elastic modulus (Table 2). Finally, as compared with samples compressed without lubricant, lubrication results in a higher significant influence of deformation rate, a similar influence of sample diameter, and a lower influence of sample height on the average $U_{\mathrm{v}}$ value, and increased friction results in a very much higher significant influence of deformation rate and sample height and a lower sample diameter influence on the average $U_{\mathrm{v}}$ value.

Two-way ANOvA analyses (Table 3 ) showed that there were significant differences between the average $\varepsilon$ values owing to the main effects of lubrication and deformation rate, and lubrication and sample height; whereas, when lubrication and sample diameter were considered in the analysis, the last factor did have non-significant effect on the failure strain. Figure 1a shows that as for nonlubricated and lubricated friction conditions, failure strain increases when the deformation rate and the sample diameter are increased and decreases when sample height is increased. Besides, as compared with samples compressed without lubricant, lubrication results in higher average $\varepsilon$ values at 200 and $400 \mathrm{~mm} \mathrm{~min}^{-1}$, at each sample height tested. Note as mainly, $\varepsilon$ values at the lowest height $(5 \mathrm{~mm})$ are significantly superior to the rest of heights (Figs 1a and 2a). When two-way ANOvA was carried out for the factors sample diameter and height (Table 3), under non-lubricated and lubricated friction conditions, neither sample diameter had significant effect on the failure strain (Fig. 2a). However, as compared with non-lubricated friction condition, increased friction results in a significant influence of sample diameter (Fig. 2a) and a 
Table 3 Multifactor analyses of variance (two-way ANova) for the failure parameters $\left(\varepsilon, F / A_{0}, F / A_{\mathrm{f}}, E, U_{\mathrm{v}}\right)$ and factors, such as lubrication and deformation rate, lubrication and sample diameter, lubrication and sample height, and sample diameter and height under non-lubricated, lubricated and increased friction conditions, respectively

\begin{tabular}{|c|c|c|c|c|c|c|c|c|c|}
\hline Source of variation & Failure parameters & F-ratio & Sig. level & Source of variation & F-ratio & Sig. level & Source of variation & F-ratio & Sig. level \\
\hline \multicolumn{10}{|l|}{ Main effects } \\
\hline \multirow[t]{5}{*}{ A: lubrication } & $\varepsilon$ & 15.542 & 0.0001 & A: lubrication & 14.940 & 0.0001 & A: lubrication & 43.257 & 0.0000 \\
\hline & $F / A_{0}$ & 0.383 & $0.5430 *$ & & 0.3425 & $0.5216^{*}$ & & 0.611 & $0.4432^{*}$ \\
\hline & $F / A_{f}$ & 27.255 & 0.0000 & & 39.483 & 0.0000 & & 30.172 & 0.0000 \\
\hline & $E$ & 0.106 & $0.7481 *$ & & 0.105 & $0.7494^{*}$ & & 0.105 & $0.7491^{*}$ \\
\hline & $U_{v}$ & 0.374 & $0.5478^{*}$ & & 0.360 & $0.5550^{*}$ & & 1.094 & $0.2959^{*}$ \\
\hline \multirow[t]{5}{*}{ B: deformation rate } & $\varepsilon$ & 10.211 & 0.0000 & B: diameter & 2.158 & $0.1423^{*}$ & B: height & 403.640 & 0.0000 \\
\hline & $F / A_{0}$ & 17.206 & 0.0000 & & 127.565 & 0.0000 & & 144.800 & 0.0000 \\
\hline & $F / A_{\mathrm{f}}$ & 27.972 & 0.0000 & & 402.237 & 0.0000 & & 48.100 & 0.0000 \\
\hline & $E$ & 22.734 & 0.0000 & & 76.284 & 0.0000 & & 25.448 & 0.0000 \\
\hline & $U_{v}$ & 13.205 & 0.0000 & & 13.163 & 0.0003 & & 434.667 & 0.0000 \\
\hline \multicolumn{10}{|l|}{ Interaction } \\
\hline \multirow[t]{7}{*}{$A B$} & $\varepsilon$ & 0.407 & $0.7479^{*}$ & $A B$ & 0.025 & $0.8767^{*}$ & $A B$ & 1.603 & $0.1876^{*}$ \\
\hline & $F / A_{0}$ & 1.309 & $0.2706^{*}$ & & 0.049 & $0.8276^{*}$ & & 10.228 & 0.0000 \\
\hline & $F / A_{\mathrm{f}}$ & 0.402 & $0.7518^{*}$ & & 0.616 & $0.4411^{*}$ & & 5.857 & 0.0006 \\
\hline & $E$ & 6.915 & 0.0001 & & 0.734 & $0.4012^{*}$ & & 2.191 & $0.0879^{*}$ \\
\hline & $U_{v}$ & 0.535 & $0.6581 *$ & & 0.007 & $0.9338^{*}$ & & 11.839 & 0.0000 \\
\hline & \multicolumn{3}{|c|}{ Non-Iubricated friction condition } & \multicolumn{3}{|c|}{ Lubricated friction condition } & \multicolumn{3}{|c|}{ Increased friction condition } \\
\hline & Failure parameters & F-ratio & Sig. level & Failure parameters & F-ratio & Sig. level & Failure parameters & F-ratio & Sig. level \\
\hline \multicolumn{10}{|l|}{ Main effects } \\
\hline \multirow[t]{5}{*}{ A: diameter } & $\varepsilon$ & 4.297 & $0.0390^{*}$ & $\varepsilon$ & 2.659 & $0.1040^{*}$ & $\varepsilon$ & 18.170 & 0.0000 \\
\hline & $F / A_{0}$ & 158.359 & 0.0000 & $F / A_{0}$ & 117.316 & 0.0000 & $F / A_{0}$ & 62.920 & 0.0000 \\
\hline & $F / A_{f}$ & 348.367 & 0.0000 & $F / A_{f}$ & 349.996 & 0.0000 & $F / A_{f}$ & - & - \\
\hline & E & 36.203 & 0.0000 & E & 66.124 & 0.0000 & E & 22.330 & 0.0000 \\
\hline & $U_{v}$ & 22.639 & 0.0000 & $U_{v}$ & 21.135 & 0.0000 & $U_{v}$ & 3.644 & $0.0572^{*}$ \\
\hline \multirow[t]{5}{*}{ B: height } & $\varepsilon$ & 255.288 & 0.0000 & $\varepsilon$ & 197.702 & 0.0000 & $\varepsilon$ & 389.588 & 0.0000 \\
\hline & $F / A_{0}$ & 190.705 & 0.0000 & $F / A_{0}$ & 55.311 & 0.0000 & $F / A_{0}$ & 575.273 & 0.0000 \\
\hline & $F / A_{\mathrm{f}}$ & 89.893 & 0.0000 & $F / A_{\mathrm{f}}$ & 27.476 & 0.0000 & $F / A_{\mathrm{f}}$ & - & - \\
\hline & $E$ & 16.589 & 0.0000 & $E$ & 14.194 & 0.0000 & $E$ & 9.733 & 0.0000 \\
\hline & $U_{v}$ & 347.841 & 0.0000 & $U_{v}$ & 160.608 & 0.0000 & $U_{v}$ & 463.781 & 0.0000 \\
\hline \multicolumn{10}{|l|}{ Interaction } \\
\hline \multirow[t]{5}{*}{$\mathrm{AB}$} & $\varepsilon$ & 8.800 & 0.0000 & $\varepsilon$ & 3.243 & $0.0223^{*}$ & $\varepsilon$ & 4.066 & 0.0074 \\
\hline & $F / A_{0}$ & 7.121 & 0.0001 & $F / A_{0}$ & 4.539 & 0.0039 & $F / A_{0}$ & 16.885 & 0.0000 \\
\hline & $F / A_{\mathrm{f}}$ & 22.176 & 0.0000 & $F / A_{\mathrm{f}}$ & 14.234 & 0.0000 & $F / A_{\mathrm{f}}$ & - & - \\
\hline & $E$ & 1.943 & $0.1226^{*}$ & $E$ & 1.881 & $0.1326^{*}$ & $E$ & 7.641 & 0.0001 \\
\hline & $U_{v}$ & 0.618 & $0.6036^{*}$ & $U_{v}$ & 0.703 & $0.5508^{*}$ & $U_{v}$ & 0.736 & $0.5313^{*}$ \\
\hline
\end{tabular}

*Non-significant differences between means $(P \leq 0.01)$; factors: lubrication (non-lubricated and lubricated friction conditions); deformation rate $(50,100$, 200 and $\left.400 \mathrm{~mm} \mathrm{~min}^{-1}\right)$; diameter (19.05 and $\left.25.4 \mathrm{~mm}\right)$; height $(5,10,15$ and $20 \mathrm{~mm}) ;(n=640$ and $n=320)$.

higher significant influence of sample height on the failure strain (Table 3). At last, as compared with nonlubricated friction condition, lubrication causes a significant increase of the failure strain, but it is not significantly influenced by increased friction (Table 4). Considering all the variables studied, sample height had the more significant effect on the failure strain. In turn, lubrication effect did not have any significant influence on the engineering stress when considered together the deformation rate, sample diameter and height effects (Table 3). Besides, although the average engineering stress increased with increasing deformation rate, only differences between 50 and $100 \mathrm{~mm} \mathrm{~min}^{-1}$ and between 100 and $200 \mathrm{~mm} \mathrm{~min}^{-1}$ were significant (Fig. 1b). How- ever, at each friction condition used, when considering sample diameter and height as main effects, both factors and their interaction had significant effect on the engineering stress (Table 3 ). The average $F / A_{0}$ value was found to decrease when sample diameter and height are increased. Under all friction conditions, the average $F / A_{0}$ values corresponding to the lowest diameter and height were significantly higher than for the rest of the sample dimensions used (Fig. 2b). Also, the failure stress, calculated on the basis of the original sample surface area, decreased with increasing sample length/diameter ratio at a constant diameter, when all other variables were kept constant (Canet \& Sherman, 1988). Again, one-way ANOVA showed that friction 

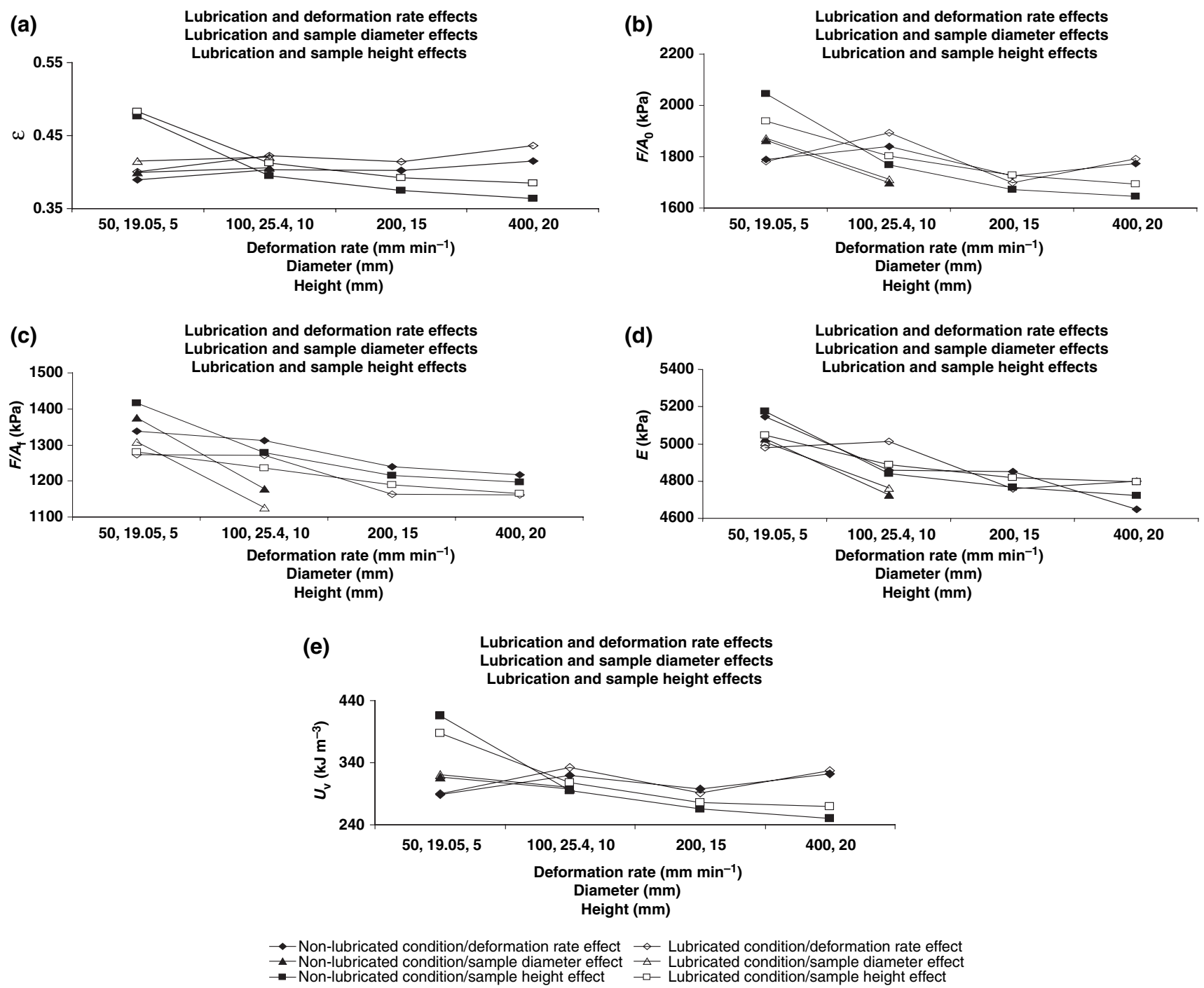

Figure 1 Effects of lubrication, deformation rate and sample dimensions on the failure parameters.

condition did not have significant effect on the engineering stress (Table 4). Between the factors studied, sample height had a more significant effect on engineering stress.

There were significant differences between the average values of the true stress $\left(F / A_{\mathrm{f}}\right)$ when all the main effects like lubrication and deformation rate, lubrication and sample diameter and lubrication and sample height were considered in the analyses (Table 3). The significance of the factors studied was very much higher for the true stress than for the engineering one, demonstrating that the use of the original area of the non-deformed sample $\left(A_{0}\right)$ replacing the actual maximum area of the deformed sample $\left(A_{\mathrm{f}}\right)$ for estimating the failure stress is not a reasonable assumption for the uniaxial compression of potato tissue. This finding contradicts other results found in cheese (Charalambides et al., 2001, 2005). As compared with non-lubricated condition, lubrication results in a lower average $F / A_{\mathrm{f}}$ value, which decreases when the deformation rate and the sample dimensions increase (Fig. 1c). The surface lubrication lowered true stress values as compared with those obtained under nonlubricated friction condition by eliminating the component of the applied force required to overcome the friction between the sample and the compression plate surfaces (Gil, 1991). A previous study showed that lubrication increased the actual area in contact with the loading plates $\left(A_{\mathrm{f}}\right)$, which was attributed to the same phenomenon (Canet et al., 2006). The two-way ANOvA carried out for factors sample diameter and height, for non-lubricated and lubricated friction conditions 
(a)

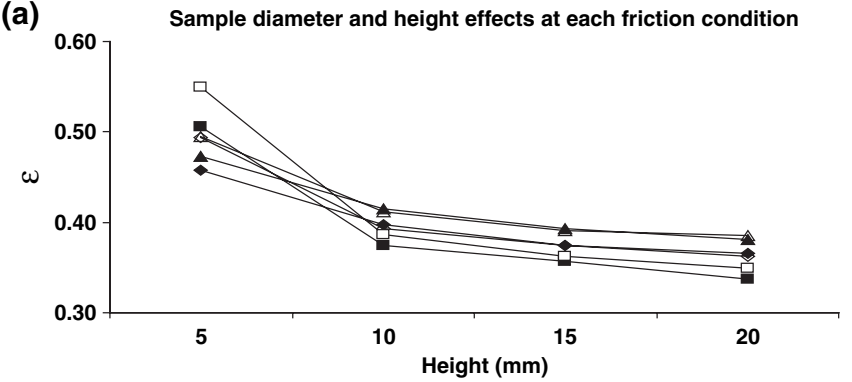

(c)

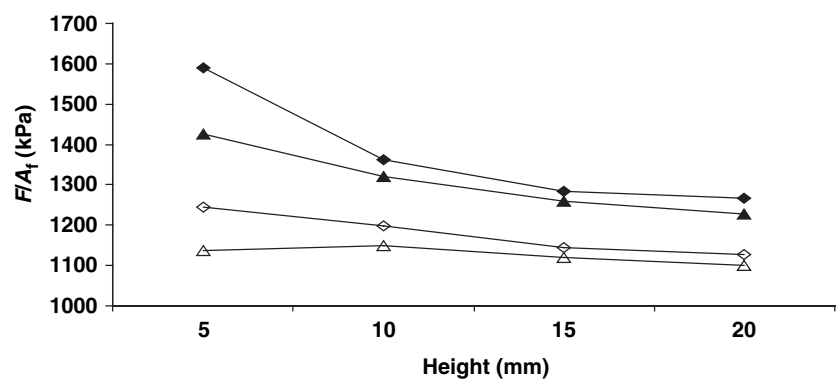

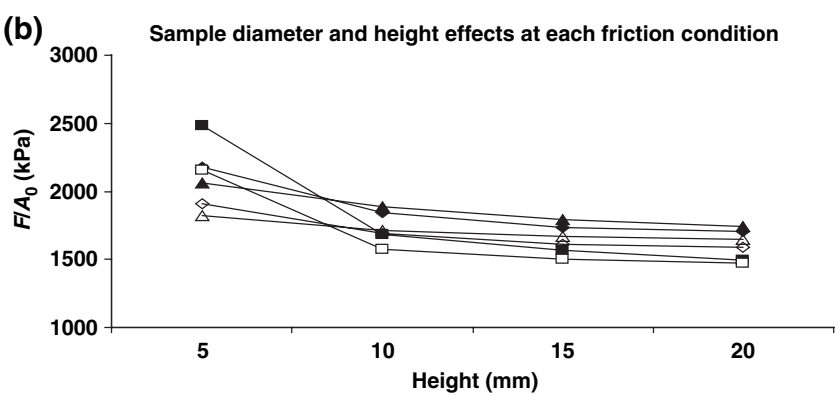

(d) Sample diameter and height effects at each friction condition

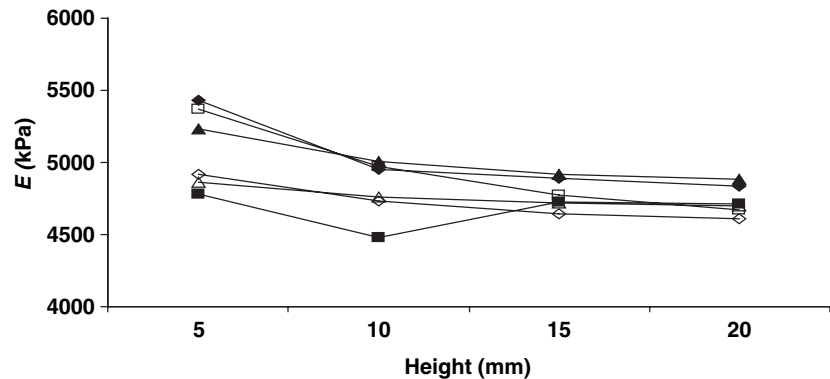

(e) Sample diameter and height effects at each friction condition

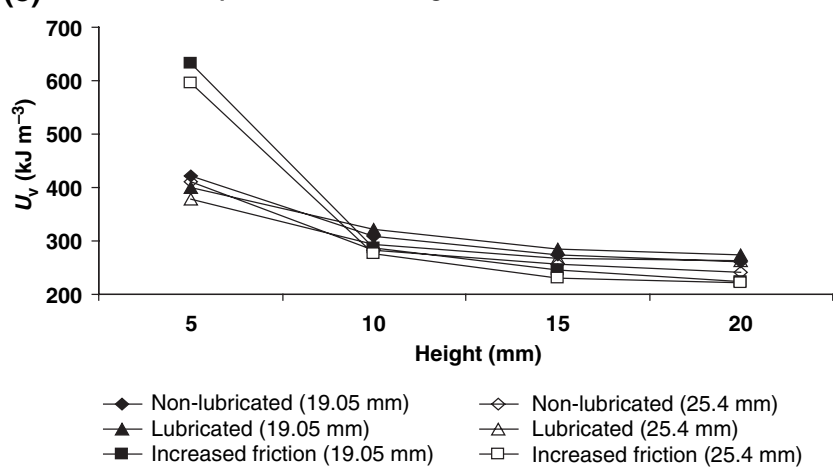

Figure 2 Effects of sample dimensions (diameter and height) on the failure parameters at each friction condition used.

indicated that both factors and their interaction had significant effect on the true stress (Table 3). For both friction conditions, the average $F / A_{\mathrm{f}}$ value is significantly decreased when both sample dimensions are increased (Fig. 2c). Finally, one-way ANOVA also demonstrated that as compared with non-lubricated friction condition, lubrication results in a significant decrease in the true failure stress (Table 4). Considering the factors studied, the sample diameter had the more significant effect on the true failure stress.

Lubrication did not have any significant effect on the apparent elastic modulus when this effect was considered together with deformation rate and sample diameter and height effects (Table 3). However, two-way ANOVA shows that there is a significant effect of deformation rate, sample diameter and height on the $E$ average value, decreasing with increasing deformation rate, sample diameter and height (Fig. 1d). At each friction condition used, both sample diameter and height had significant effect on the apparent elastic modulus (Table 3), which is significantly higher at the smallest sample dimensions (Fig. 2d). Besides, friction condition had non-significant effect on the $E$ average value when all friction conditions and only nonlubricated and lubricated friction conditions are considered (Table 4). Among the factors studied, sample diameter had the more significant effect on the apparent elastic modulus.

Lubrication had no significant effect on the energy at failure when considered together with deformation rate 
Table 4 Analyses of variance (one-way ANOvA) and comparisons between means for the failure parameters $\left(\varepsilon, F / A_{0}, F / A_{\mathrm{f}}, E, U_{\mathrm{v}}\right)$ with three and two friction levels, respectively

\begin{tabular}{|c|c|c|c|c|c|c|}
\hline Source of variation & Failure parameters & F-ratio & Sig. level & Non-lubricated & Lubricated & Increased friction \\
\hline \multirow[t]{5}{*}{ A: friction } & $\varepsilon$ & 6.185 & 0.0021 & $40.2545 a$ & $41.8193 b$ & $40.3112 a$ \\
\hline & $F / A_{0}$ & 3.071 & $0.0468^{*}$ & $1781.9984 a$ & $1791.4188 a$ & $1741.1987 a$ \\
\hline & $F / A_{f}$ & 417.005 & 0.0000 & 1276.7956a & $1217.3753 b$ & $1741.1987 \mathrm{c}$ \\
\hline & $E$ & 2.372 & $0.0938^{*}$ & $4876.2962 a$ & $4886.5216 a$ & $4811.3403 a$ \\
\hline & $U_{v}$ & 7.367 & 0.0007 & $307.0100 \mathrm{a}$ & $310.2594 a$ & $339.3234 b$ \\
\hline \multirow[t]{5}{*}{ A: lubrication } & $\varepsilon$ & 14.936 & 0.0001 & $40.2545 a$ & $41.8193 b$ & \\
\hline & $F / A_{0}$ & 0.355 & $0.5578^{*}$ & $1781.9984 a$ & $1791.4188 a$ & \\
\hline & $F / A_{\mathrm{f}}$ & 24.248 & 0.0000 & $1276.7956 a$ & $1217.3753 b$ & \\
\hline & E & 0.094 & $0.7625^{*}$ & $4876.2962 a$ & $4886.5216 a$ & \\
\hline & $U_{v}$ & 0.354 & $0.5584^{*}$ & $307.0100 \mathrm{a}$ & $310.2594 a$ & \\
\hline
\end{tabular}

*Non-significant differences between means $(P \leq 0.01)$; factors: friction (non-lubricated, lubricated and increased friction conditions); lubrication (nonlubricated and lubricated friction conditions).

a, bifferent letters in the same row for each source indicate significant differences ( $n=960$ and $n=640$, respectively).

and sample diameter and height effects (Table 3), although two-way ANOvA shows that there is a significant effect of deformation rate, sample diameter and height on the average $U_{\mathrm{v}}$ value, which increased when deformation rate was increased and decreased when sample dimensions were increased (Fig. 1e). The values of energy at failure corresponding to heights of 5 and $10 \mathrm{~mm}$ are significantly higher than those corresponding to the heights of 15 and $20 \mathrm{~mm}$. For non-lubricated and lubricated friction conditions, sample diameter and height did have significant effect on the energy at failure (Table 3), whereas only sample height had significant effect for increased friction condition. Sample height was the factor that more significantly influenced the energy at failure, with average $U_{\mathrm{v}}$ values significantly higher at the lowest height (Fig. 2e). As compared with non-lubricated friction condition, lubrication did not have significant influence on the energy at failure, but it is significantly increased under increased friction (Table 4).

The influence of surface lubrication was smaller than would be anticipated from previous studies with Gouda cheese (Culioli \& Sherman, 1976). These authors did not derive any compression parameter from the stresscompression curves generated under non-lubricated, lubricated and increased friction conditions. However, comparisons between them indicate that lubrication and friction effects had a high and significant influence on the force-compression behaviour. In this study, lubrication did not have significant effect on the engineering stress, the apparent elastic modulus and the energy at failure $\left(U_{\mathrm{v}}\right)$. Lubrication resulted in an increase of the failure strain (approximately 4\%) and in a decrease of the true stress (approximately 5\%) as compared with those values obtained under non-lubricated condition (Table 4). The relatively small effect exerted by surface lubrication on the failure strain and the true stress could be attributed to the release of fluid from the damaged tissue of the potato flesh, which relatively reduced lubricant effectiveness (Canet \& Sherman, 1988, 1990; Canet et al., 2006).

\section{Principal components analyses}

Table 5 shows the two components extracted at each analysis having eigenvalues greater than or equal to 1.0 . Figure 3 shows the biplots of the two principal components for the failure parameters. Each plot contains the scatterplot of the principal components and a line for each failure parameter reflecting how each parameter contributes to the components. PCA revealed that two principal components accounted for $\geq 95 \%$ of the total variability (Table 5$)$, when four failure parameters $(\varepsilon$, $\left.F / A_{0}, E, U_{\mathrm{v}}\right)$ were included in the PCA analyses (Fig. 3a), whereas the total variability explained by the first and second axes was slightly lower $(<90 \%)$ when six parameters $\left(\varepsilon, F / A_{0}, F / A_{\mathrm{f}}, E, U_{\mathrm{v}}, A_{\mathrm{f}} / A_{0}\right)$ were considered (Fig. 3b). The area of expansion ratio at failure $\left(A_{\mathrm{f}} / A_{0}\right)$ could be considered as a geometrical variable but is not a failure parameter by itself, which

Table 5 Principal components analyses (PCA) under different friction conditions and with different number of failure parameters

\begin{tabular}{|c|c|c|c|c|}
\hline \multirow{2}{*}{$\begin{array}{l}\text { Component } \\
\text { number }\end{array}$} & \multicolumn{2}{|c|}{ All friction conditions (with four failure parameters) } & \multicolumn{2}{|c|}{ Non-lubricated and lubricated friction conditions (with six failure parameters) } \\
\hline & Eigenvalue & Percent of variance & Eigenvalue & Percent of variance \\
\hline 1 & 2.7546 & 68.865 & 3.2819 & 54.698 \\
\hline 2 & 1.0465 & 26.162 & 1.9388 & 32.314 \\
\hline
\end{tabular}



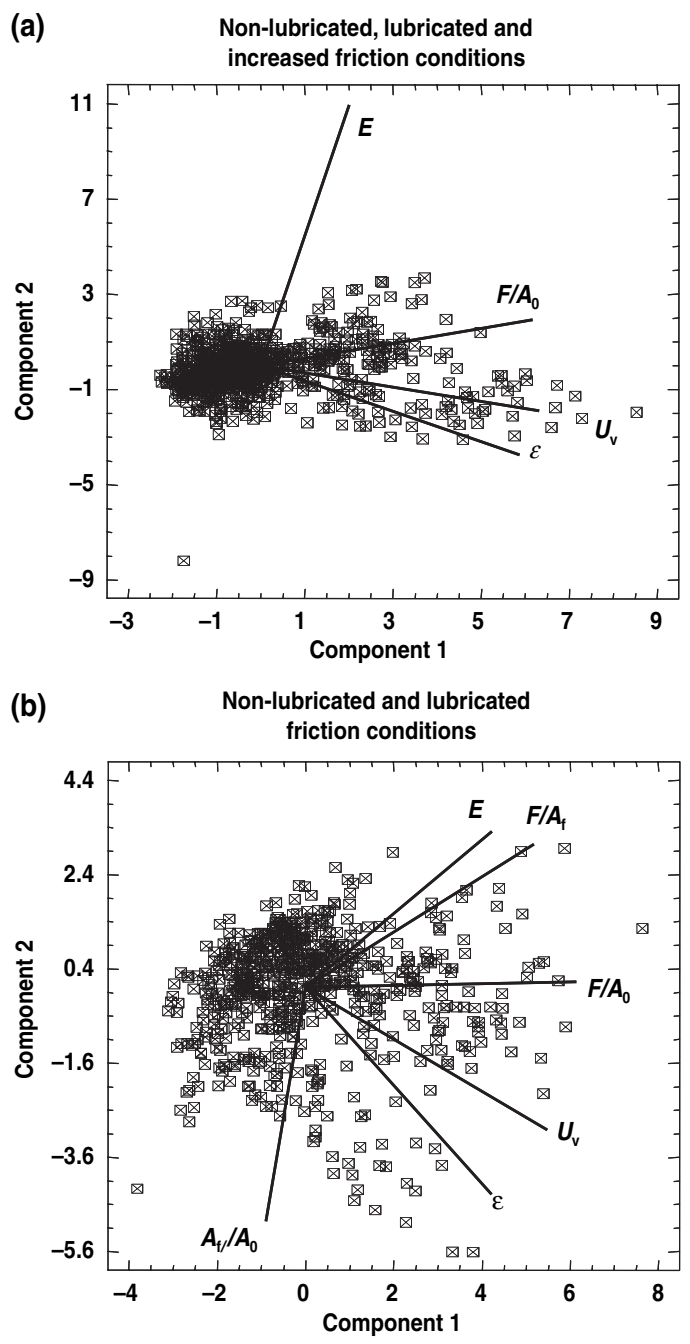

Figure 3 Biplots for the first two principal components from the two principal components analyses (PCA) carried out.

justifies that its inclusion in the PCA analysis decreased the percentages of each failure parameter explained by the first two principal axes. Table 6 gives the weights of the linear combinations that form the two principal components. When four failure parameters were taken into account for data totality, including all friction conditions (Fig. 3a), all the failure parameters positively weight component 1 , and this factor is almost equally weighted on the failure strain $(\varepsilon)$, engineering stress $\left(F / A_{0}\right)$ and energy at failure $\left(U_{\mathrm{v}}\right)$ ratings. The failure strain and energy at failure slightly and negatively weight component 2 , which is positively dominated by the apparent elastic modulus $(E)$. Certainly, the relationship between internal cell pressure and apparent elastic modulus has been well established for potato tissue (Canet, 1980; Canet \& Sherman, 1988, Gil, 1991; Alvarez \& Canet, 1998), and this link appears to keep either under non-lubricated and lubricated conditions or especially under increased friction condition. It is worth nothing that by considering only non-lubricated and lubricated friction conditions, component 2 is not dominated by the apparent elastic modulus. If compression is performed under conditions where there is friction, the cell walls are in an apparently high state of tension and with a high internal cell pressure, which reinforce the idea of the connection existing between internal cell pressure and apparent elastic modulus.

From Table 6, considering all friction conditions (Fig. 3a), the first component equals:

$$
0.5441(\varepsilon)+0.5721\left(F / A_{0}\right)+0.1867(E)+0.5846\left(U_{\mathrm{v}}\right)
$$

This linear combination appears to reflect a single factor related to the mechanical response of the potato tissue to deformation and cell-wall rupture (Alvarez \& Canet, 1998), which besides would be strongly influenced by the sample height as found for the failure strain, the engineering stress and the energy at failure separately.

The second component is given by:

$$
-0.3163(\varepsilon)+0.1630\left(F / A_{0}\right)+0.9209(E)-0.1592\left(U_{\mathrm{v}}\right)
$$

and can be related to the internal cell pressure, being strongly influenced by sample diameter.

In turn, in addition to the four failure parameters derived directly from the force-deformation curves, the area expansion ratio at failure $\left(A_{\mathrm{f}} / A_{0}\right)$ and the true stress $\left(F / A_{\mathrm{f}}\right)$ are considered in the analyses (Fig. $3 \mathrm{~b}$ ). Also, all the failure parameters positively weight com-

\begin{tabular}{|c|c|c|c|c|}
\hline & \multicolumn{2}{|c|}{$\begin{array}{l}\text { All friction conditions (with four failure } \\
\text { parameters) }\end{array}$} & \multicolumn{2}{|c|}{$\begin{array}{l}\text { Non-lubricated and lubricated friction conditions } \\
\text { (with six failure parameters) }\end{array}$} \\
\hline & Component 1 & Component 2 & Component 1 & Component 2 \\
\hline$\varepsilon$ & 0.5441 & -0.3163 & 0.3982 & -0.4529 \\
\hline$F / A_{0}$ & 0.5721 & 0.1630 & 0.5338 & 0.0919 \\
\hline$F / A_{\mathrm{f}}$ & - & - & 0.4264 & 0.4165 \\
\hline$E$ & 0.1867 & 0.9209 & 0.3484 & 0.3848 \\
\hline$U_{v}$ & 0.5846 & -0.1592 & 0.4979 & -0.2688 \\
\hline$A_{\mathrm{f}} / A_{0}$ & - & - & 0.0742 & -0.6266 \\
\hline
\end{tabular}

Table 6 Equations of the principal components under the two principal components analyses (PCA) carried out 
ponent 1 , and this factor is almost equally weighted on the engineering stress and the energy at failure ratings. Note the variable $A_{\mathrm{f}} / A_{0}$, positive but inconsiderately weight component 1 (Table 6). However, although the apparent elastic modulus $(E)$ and the true stress $\left(F / A_{\mathrm{f}}\right)$ positively weight component 2 , this factor is negatively dominated by the area expansion ratio $\left(A_{\mathrm{f}} / A_{0}\right)$. Components 1 and 2 were almost equally weighted on the failure strain although with different sign. This means that the greater the observed area in contact with the loading plates with respect to original area, the lower either the apparent elastic modulus or the true stress. A previous study showed that indeed high correlations are established between the true stress and apparent elastic modulus for non-lubricated and lubricated friction conditions (Canet et al., 2006).

\section{Conclusions}

Deformation rate $\left(R_{\mathrm{d}}\right)$ and sample dimensions $(\emptyset$ and $h)$ influenced the failure parameters derived from uniaxial compression of potato. As compared with non-lubricated friction condition, surface lubrication increased the failure strain (approximately 4\%) and decreased the true failure stress (approximately 5\%), but appeared to have a low effect on the rest of the failure parameters. Under non-lubricated friction condition, the average $\varepsilon$ value was found to increase when the deformation rate and the sample diameter were increased (approximately $7 \%$ and $2 \%$ respectively), and to decrease when the sample height is increased (approximately 24\%). The average $F / A_{0}$ and $U_{\mathrm{v}}$ values were found to increase when the $R_{\mathrm{d}}$ is increased (approximately $8 \%$ and $11 \%$, respectively), and mainly to decrease when the $\emptyset$ and $h$ are increased (approximately $9 \%$ and $6 \%$, respectively for $\emptyset$, and $20 \%$ and $40 \%$, respectively for $h$ ). The average $F / A_{\mathrm{f}}$ and $E$ values were found to decrease significantly when the $R_{\mathrm{d}}, \emptyset$ and $h$ were increased (approximately $9 \%$ and $10 \%$, respectively for $R_{\mathrm{d}}, 14 \%$ and $6 \%$, respectively for $\emptyset$, and $15 \%$ and $8 \%$, respectively for $h$ ). As compared with non-lubricated condition, lubrication results in a higher influence of the deformation rate on the average $\varepsilon, F / A_{0}$ and $U_{\mathrm{v}}$ values, a similar influence of sample diameter on the average $F / A_{\mathrm{f}}$ and $E$ values, but a lower influence of sample height on all the failure parameters. Increased friction results in a higher influence of $R_{\mathrm{d}}$ and $h$ on the average $\varepsilon, F / A_{0}$ and $U_{\mathrm{v}}$ values, and a lower influence of $\emptyset$ on all the failure parameters. Sample height is the factor that had the more significant effect on the $\varepsilon, F / A_{0}$ and $U_{\mathrm{v}}$ parameters, dominating the component 1 derived from PCA analyses. Sample diameter had the more significant effect on the $F / A_{\mathrm{f}}$ and $E$ parameters, mainly $E$ dominating component 2. In an industrial environment, experiment setting can be suggested as follows: the surface of sample is not to be lubricated, deformation rate should be intermediate-high $\left(R_{\mathrm{d}}=200 \mathrm{~mm} \mathrm{~min}{ }^{-1}\right)$, and samples have to be made with large diameter $(\emptyset=25.4 \mathrm{~mm})$ and intermediate-high height $(h=15 \mathrm{~mm})$.

\section{Acknowledgements}

The authors wish to thank the CICyT for financial support (AGL2004-01780/ALI). This work has been prepared in memory of Dr M.J. Gil, recently deceased, based on the results of his $\mathrm{PhD}$ carried out under the direction of Dr W. Canet at the Instituto del Frío-CSIC, Spain.

\section{References}

Alvarez, M.D. \& Canet, W. (1998). Rheological characterization of fresh and cooked potato tissues (cv. Monalis). Zeitschrift für Lebensmittel Untersuchung und Forschung A, 207, 55-65.

Alvarez, M.D. \& Canet, W. (2000). Principal component analysis to study the effect of temperatura fluctuations during storage of frozen potato. European Food Research and Technology, 211, 415-421.

Alvarez, M.D., Canet, W. \& López, M.E. (2002). Influence of deformation rate and degree of compression on textural parameters of potato and apple tissues in texture profile analysis (TPA). European Food Research and Technology, 215, 13-20.

Barreiro, P., Ortiz, C., Ruiz-Altisent, M., et al. (1998). Comparison between sensory and instrumental measurements for mealiness assessment in apples. A collaborative test. Journal of Texture Studies, 29, 509-525.

Canet, W. (1980). Estudio de la influencia de los tratamientos térmicos de escaldado, congelación y descongelación en la textura y estructura de patata (Solanum tuberosum, L.). PhD Thesis, Universidad Politécnica de Madrid: Madrid.

Canet, W. \& Sherman, P. (1988). Influence of friction, sample dimensions and deformation rate on the uniaxial compression of raw potato flesh. Journal of Texture Studies, 19, 275-287.

Canet, W. \& Sherman, P. (1990). Effect of friction, sample dimensions, and deformation rates on the uniaxial compression behaviour of potato tissues. In: Engineering and food physical properties and process control (edited by W.E L. Spiess \& H. Schubert). Pp. 159168. Vol. I. London: Elsevier Applied Science.

Canet, W., Alvarez, M.D. \& Fernández, C. (2005). Optimization of low-temperature blanching for retention of potato firmness: effect of previous storage time on compression properties. European Food Research and Technology, 221, 423-433.

Canet, W., Alvarez, M.D. \& Gil, M.J. (2006). Modelling the area expansion ratio on uniaxial compression of cylindrical potato samples. Journal of Food Engineering (in press).

Canet, W., Alvarez, M.D., Luna, P., Fontecha, J. \& Juarez, M. (2001) IDF-Collaborative study of uniaxial compression of cheese Standing Committee on Minor Components \& characterization of physical properties.

Charalambides, M.N., Goh, S.M., Lim, S.L. \& Williams, J.G. (2001). The analysis of the frictional effect on stress-strain data from uniaxial compression of cheese. Journal of Materials Science, 36, 2313-2321

Charalambides, M.N., Goh, S.M., Wanigasooriya, L., Williams, J.G. \& Xiao, W. (2005). Effect of friction on uniaxial compression of bread dough. Journal of Materials Science, 40, 3375-3381.

Chu, C.F. \& Peleg, M. (1985). The compressive behaviour of solid food specimens with small height to diameter ratios. Journal of Texture Studies, 16, 451-464.

Culioli, J. \& Sherman, P. (1976). Evaluation of Gouda cheese firmness by compression tests. Journal of Texture Studies, 7, 353-372. 
Dieter, G. (1986). Mechanical Metallurgy. 3rd ed. New Cork: McGraw Hill Book Company.

Gil, M.J. (1991).Estudio del efecto de la fricción, dimensión de las muestras y velocidades de deformación en ensayos de compresión uniaxial de alimentos sólidos. PhD Thesis, Universidad Politécnica de Madrid: Madrid.

Goh, H.C. \& Sherman, P. (1987). The influence of surface friction on the stress relaxation of Gouda cheese. Journal of Texture Studies, $\mathbf{1 8}$, 389-404.

ISO/TS 17996/IDF/RM 205: 2006(E). Cheese-determination of rheological properties by uniaxial compression at constant displacement rate.

Johnson, W. \& Mellor, P.B. (1973). Engineering Plasticity. London: Van Nostrand Reinhold Company Ltd.

Luginbühl, W. (1996). The effect of stress correction on fracture point coordinates in uniaxial compression tests of cheese. LebensmittelWissenschaff-und-Technologie, 29, 433-437.

Luyten, H., Van Vliet, T. \& Walstra, P. (1992). Comparison of various methods to evaluate fracture phenomena in food material. Journal of Texture Studies, 23, 245-266.

Olkku, J. \& Sherman, P. (1979). Compression testing of cylindrical samples with an Instron Universal Testing machine. In: Food texture and rheology (edited by P. Sherman). Pp. 157-175. London: Academic Press.
Piggot, J.R. \& Sharman, K. (1986). Methods to aid interpretation of dimensional data. In: Statistical Procedures in Food Research (edited by J. R Piggot \& K. Sharman). Pp. 181-232. London: Elsevier Science.

Scanlon, M.G. \& Long, A.E. (1995). Fracture strengths of potato tissue under compression and tension at two rates of loading. Food Research International, 28, 397-402.

Silva, M.L. \& Macalta, F.X. (1999). Effects of time of grape pomace fermentation and distillation cuts on the chemical composition of grape marcs. Zeitschrift für Lebensmittel Untersuchung und Forschung A, 208, 134-143.

Smith, C.V. \& Kobayashi, A.S. (1993). Experimental fracture mechanics. In: A Handbook on Experimental Mechanics (edited by S. Kobayashi). Pp. 905-968. New York: VCH Publishers.

Smith, O. (1987). Transport and storage of potatoes. In: Potato Processing (edited by W.F. Talburt \& O. Smith). Pp. 203-285. New York: Van Nostrand Reinnold.

Varela, F., Calderón, F., González, M.C., Colomo, B. \& Suárez, J.A. (1999). Effect of clarification on the fatty acid composition of grape must and the fermentation kinetics of white wines. European Food Research and Technology, 209, 439-444.

Wagoner, R.H. \& Chenot, J.-L. (2005). Metal Forming Analysis. Cambridge: Cambridge University Press. 